\title{
МЕХАНИЧЕСКИЕ СВОЙСТВА ПОЛОСЫ ИЗ СПЛАВА Д16, ПОЛУЧЕНОЙ МЕТОДОМ ВАЛКОВОЙ РАЗЛИВКИ
}

\author{
${ }^{1}$ А.В.Ноговицын, ${ }^{1}$ А.С.Нурадинов, ${ }^{1}$ А.Л.Гончаров, ${ }^{2}$ В.С.Воропаев, ${ }^{1}$ И.Р.Баранов \\ 1 - Физико-технологический институт металлов и сплавов (ФТИМС) НАН \\ Украины, г. Киев, Украина \\ 2 - Институт материаловедения им. И.М. Францевича НАН Украины, \\ г. Киев, Украина
}

В последние году в металлургии развивается метод изготовления листового проката, который заключается в совмещении операций литья и прокатки. Вследствие высокоскоростной кристаллизации существуют широкие возможности влияния на структуру и свойства металла, создаются условия для получения материала с мелкозернистой структурой и повышенными механическими характеристиками [1]. Впервые в мировой практике во ФТИМС НАН Украины удалось получить методом валкового литья ленту алюминиевого сплава Д16 (рис.1), который имеет широкий температурный интервал затвердевания (>130 ㄷ).

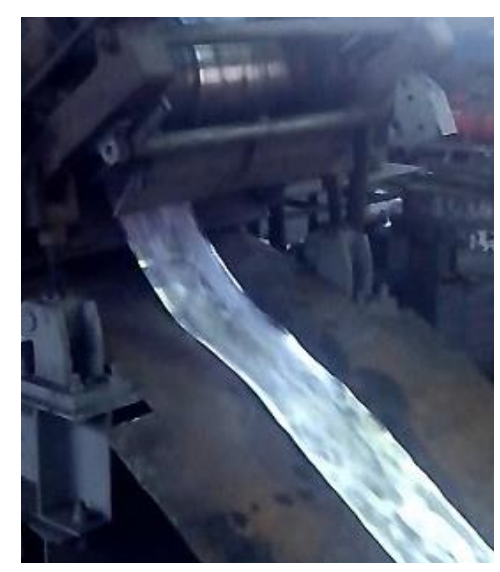

$a$

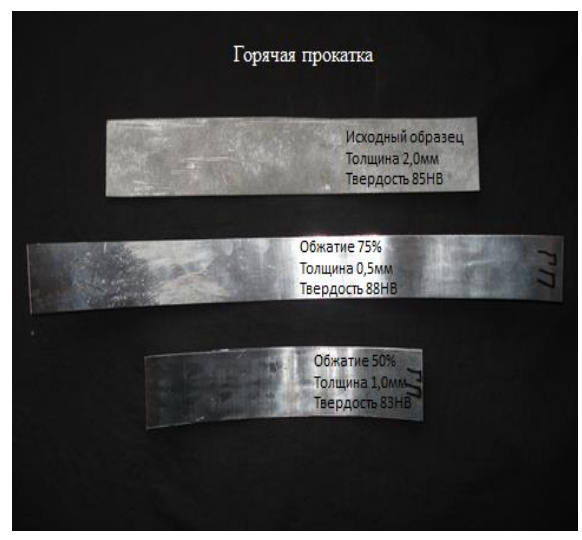

$\sigma$

Рис. 1. Литье полосы на валковой установке $(a)$ и внешний вид образцов (б) из сплава Д16 после литья и горячей прокатки 
Структура $\alpha$-твердого раствора алюминия в листе, полученном на валковой установке, состоит из первичных кристаллов различной дисперсности. В структуре наблюдаются кристаллы размером 180-250 мкм со средней величиной дендритной ячейки 50 мкм. Большой объем в структуре сплава занимают кристаллы размером 25-50 мкм с дендритными ячейками, средний размер которых не превышает 8 мкм. Также в достаточно однородной структуре сплава присутствуют дисперсные интерметаллидные и эвтектические фазы, которые расположены между ветвями первичных кристаллов.

Полученный на валковой разливной машине лист толщиной 2 мм прокатывали в горячем и холодном состоянии. Горячую деформацию листа осуществляли в несколько проходов при температуре $420^{\circ} \mathrm{C}$ со степенью суммарного обжатия $\sim 90 \%$. Установлено, что после горячей прокатки повышается качество поверхности листа и обеспечивается постоянная толщина по его длине и ширине. Изменения внешнего вида образцов после горячей и холодной прокатки литой полосы приведены на рис.1, д.

Были проведены прокатки литых лент размерами $40 \div$ $50 x 100 \div 200$ мм. При прокатке ленты отбирали образцы с разной степенью обжатия. Отобранные образцы были термически обработаны методом закаливания с естественным старением. Затем были определены их механические свойства путем механических испытаний на растяжение.

На рис. 2 приведены зависимости предела прочности $\sigma_{B}$ и относительного удлинения $\delta$ от степени обжатия $\sum_{\mathrm{i}}=\frac{h_{0}}{h_{i}}$ $\left(\mathrm{h}_{0}\right.$-толщина литой полосы, $\mathrm{h}_{\mathrm{i}}$ - толщина полосы после $\mathrm{i}$-го обжатия). 

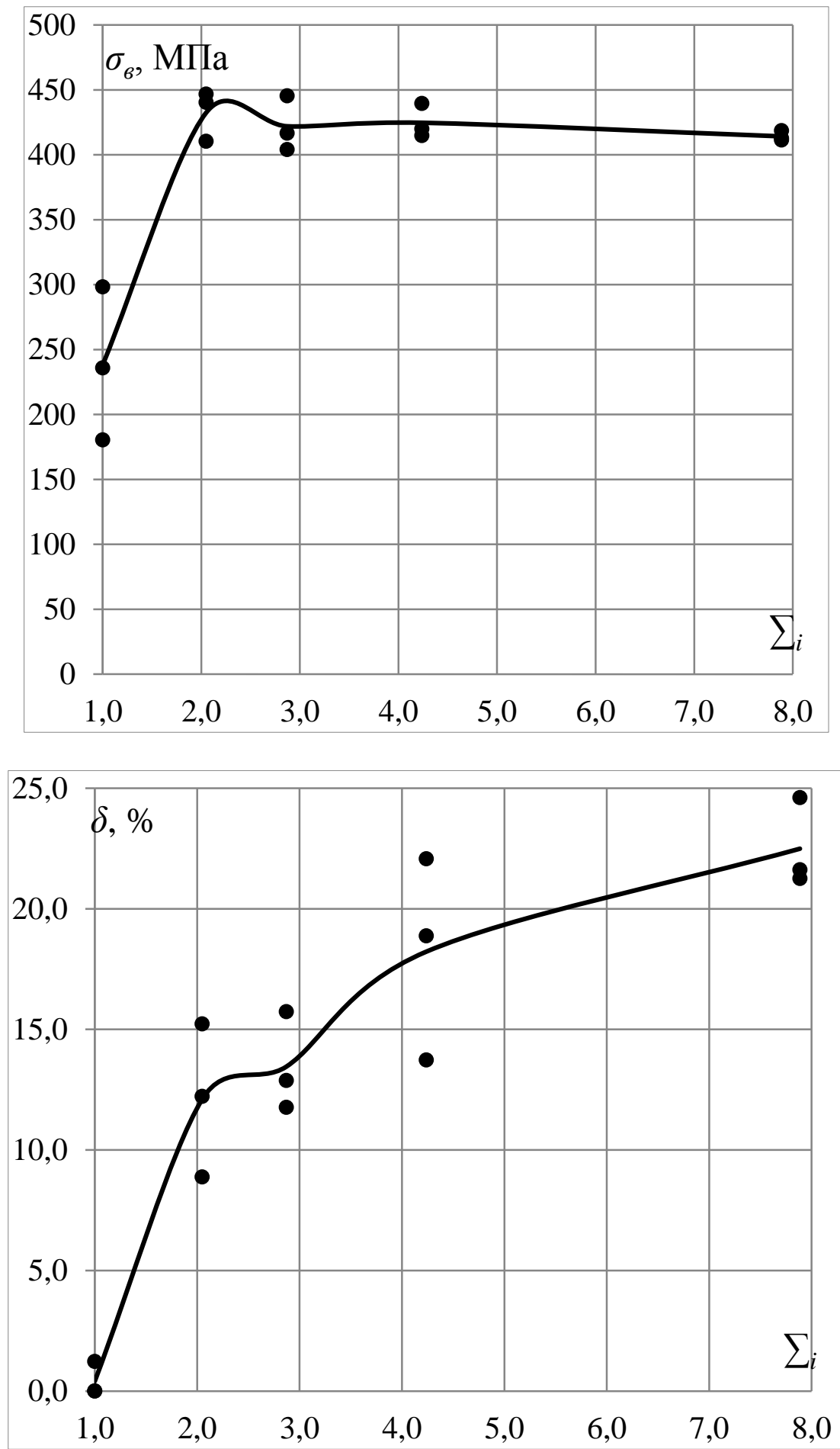

Рис. 2. Экспериментальные данные зависимости предела прочности $\sigma_{B}($ a) и относительного удлинения $\delta$ полосы из сплава Д16 от степени обжатия $\sum_{\mathrm{i}}$ при горячей прокатке 
Из приведенных данных следует, что литая лента $(\Sigma=1)$ имеет низкую прочность и пластичность. После горячей деформации $50 \%(\Sigma=2)$ предел прочности $\sigma_{B}$ достигает максимального значения. При этом относительное удлинение $\delta$ также существенно увеличилось и продолжает расти с увеличением деформации.

Вывод: Горячая прокатка лент из сплава Д16, полученных методом валкового литья, существенно увеличивает их механические свойства. Предел прочности ленты приобретает максимума при горячей деформации 50\%. Пластичность ленты имеет тенденцию к росту и при дальнейшем увеличении степени деформации.

\section{Литература}

1. Гридин А.Ю. Получение полос из высокопрочных алюминиевых сплавов валковой разливкой-прокаткой / А.Ю. Гридин, М. Шапер, В.Н. Данченко // Обработка металлов давлением. - 2011. - № 3 (28). - С. 184 $-194$. 